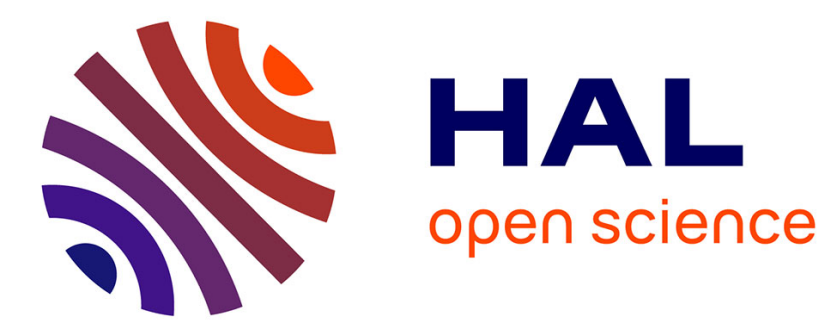

\title{
SAR Assessment and Analysis of Cumulative Body Exposure to Multi Transmitters from a Mobile Phone
}

\author{
Zaher Mahfouz, Azeddine Gati, David Lautru, Joe Wiart, Victor Fouad
} Hanna

\section{- To cite this version:}

Zaher Mahfouz, Azeddine Gati, David Lautru, Joe Wiart, Victor Fouad Hanna. SAR Assessment and Analysis of Cumulative Body Exposure to Multi Transmitters from a Mobile Phone. 2012 IEEE Topical , Jan 2012, Santa Clara, CA United States. pp.77 - 80 10.1109/BioWireless.2012.6172726 . hal-00693365

\section{HAL Id: hal-00693365 \\ https://hal.science/hal-00693365}

Submitted on 2 May 2012

HAL is a multi-disciplinary open access archive for the deposit and dissemination of scientific research documents, whether they are published or not. The documents may come from teaching and research institutions in France or abroad, or from public or private research centers.
L'archive ouverte pluridisciplinaire HAL, est destinée au dépôt et à la diffusion de documents scientifiques de niveau recherche, publiés ou non, émanant des établissements d'enseignement et de recherche français ou étrangers, des laboratoires publics ou privés. 


\title{
SAR Assessment and Analysis of Cumulative Body Exposure to Multi Transmitters from a Mobile Phone
}

\author{
Zaher Mahfouz $^{1,3}$, Azeddine Gati ${ }^{1}$ (Member IEEE), David Lautru ${ }^{3}$ (Member IEEE), Joe Wiart ${ }^{1,2}$ (Senior \\ Member IEEE) and Victor Fouad Hanna ${ }^{3}$ (Fellow IEEE) \\ ${ }^{1}$ France Télécom Division R\&D RESA: FACE 38-40, rue Général Leclerc \\ 92794 Issy Les Moulineaux, France \\ ${ }^{2}$ Whist Lab: Orange Labs \& Institut Telecom Common Lab \\ \{zaher.mahfouz;azeddine.gati;joe.wiart\}@orange-ftgroup.com \\ ${ }^{3}$ UPMC Univ Paris 06, UR2, L2E, F-75005, Paris, France \\ \{david.lautru;victor.fouad_hanna\}@upmc.fr
}

\begin{abstract}
This paper presents results for the Specific Absorption Rate (SAR) when using a mobile phone equipped with a multiple antenna system. The SAR is evaluated using the Finite Difference Time Domain (FDTD) method for different configurations taking into account all possible simultaneous transmission from a mobile phone. The considered signals are GSM900, GSM1800, UMTS2100 and WiFi2400. The results show that the calculated local SAR for the different configurations never exceeds the limit of $2 \mathrm{~W} / \mathrm{Kg}$ recommended by ICNIRP. It was demonstrated also that the maximum of the sum of the SAR evaluated from two different transmitters is always less than the sum of the maximum evaluated ones from each transmitter separately.

Index Terms - SAR, Multiple exposure, Radiofrequency
\end{abstract}

\section{INTRODUCTION}

Increasing use of wireless devices continues to generate concern about potential health effects on humans. Basic restrictions of electromagnetic field exposure have been established by the International Commission on Non Ionizing Radiation Protection (ICNIRP) [1] and the Institute of Electronics and Electrical Engineers (IEEE) [2] and followed by technical standardization bodies like CENELEC [3] to protect the public against possible negative health effects of radiofrequency electromagnetic radiation. Basic restriction is verified by performing specific absorptions rate (SAR) evaluation. The basic restriction was set by ICNIRP to a maximum value of $2 \mathrm{~W} / \mathrm{Kg}$ for the SAR averaged over $10 \mathrm{~g}$ (SAR10g). Not all standards and guidelines throughout the world have recommended the same limits for exposure. However, published exposure limits by ICNIRP are the same in North America and in some parts of Europe (for example in France).

Exposure from multiple EM sources is quite common, particularly in the case of simultaneous exposure from multiple broadcast and cellular infrastructure transmitters. In fact, the body exposure to RF depends on the characteristics of the signal and on the environment. The different systems operate with different protocols in different frequency bands. Therefore, humans are exposed to various types of radio emissions. Each signal has its proper behavior (transmitted power, power control, data rate, bandwidth, modulations, duty cycle, transmission...) and its access mode like Frequency Division Multiple Access (FDMA), Time Division Multiple Access (TDMA) and Code Division Multiple Access (CDMA).

Over the last few years combined data and voice communication systems have been deployed. There is also a growing number of personal communication devices that allow simultaneous transmission over multiple air-interfaces while being operated near the user's body.

The smart phones can be used to transmit voice and data at the same time. They contain multiple transmitters operating at widely spaced frequencies. The emissions from these uncorrelated sources with a wide frequency separation have to be combined.

A mobile phone equipped with a multiple antenna system has been investigated in [4]. It was demonstrated that using MIMO techniques at the transmitter allows a reduction of the exposure by some $95 \%$. This technique uses multiple antennas emitted at the same frequency band. In this case the sources are correlated.

In this paper, the SAR is evaluated for different configurations taking into account all possible uncorrelated simultaneous transmission operating at widely spaced frequencies from a mobile phone using the Finite Difference Time Domain (FDTD) techniques.

\section{SAR CALCULATIONS}

\section{A. Source Model}

In this study, a phone model (Fig.1) having two antennas is used. Some representative phone mobile models are proposed in [5]. The models were validated in presence of the body by SAR distribution experimental measurements. 
(a)
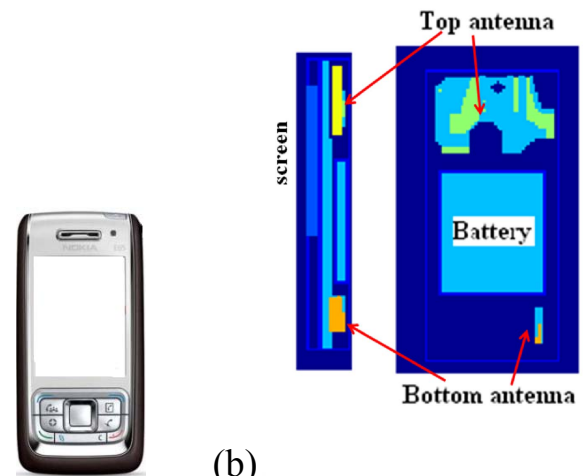

(b)

Fig. 1. Phone Model: commercial model (1.a), representative phone cross sections(1.b)

One of the mobile phone models [5] proposed with an antenna on the top of the mobile is selected for this study. This top antenna is adapted for different frequency bands, GSM bands (900 MHz and $1800 \mathrm{MHz}$ ) and UMTS band $(2100 \mathrm{MHz})$. A second antenna on the bottom is adapted for Wi-Fi frequency band $(2400 \mathrm{MHz})$. The cell phone is modeled using patch antennas.

The representative model consists of the casing, the frame, the screen, the Printed Circuit Board (PCB), the two patch antennas and the battery (Fig (1.b)). The casing, the frame and the screen are modeled as a plastic material. The PCB is implemented as a metallic plaque having standard PCB dimensions. The screen is considered as a plastic material with a back metal plaque, and the battery is considered as a metallic box with a plastic cover.

\section{B. FDTD and SAR}

The SAR is evaluated in a liquid tissue (Fig. 2) (plane phantom). The permittivity and conductivity of simulated liquid representing human tissues and prepared for SAR evaluation are appropriate for the device operating frequencies [6]. A liquid tissue is used and not a head model in simulations to simplify and to easy compares the different configurations. For each transmitter, the permittivity and conductivity of simulated liquid tissue are selected according to the frequency of the source. The Finite Difference the Time Domain (FDTD) method is used to evaluate the SAR. A rectangular computational grid, based on the Yee cell has been employed, using the well known leap frog scheme, with a spatial resolution of $1 \mathrm{~mm}$ and the PML absorbing boundary conditions to avoid spurious reflections at the boundary of the limited computational domain. The SAR is defined as:

$$
S A R=\frac{\sigma E^{2}}{2 \rho},\left[\amalg E_{K g}\right]
$$

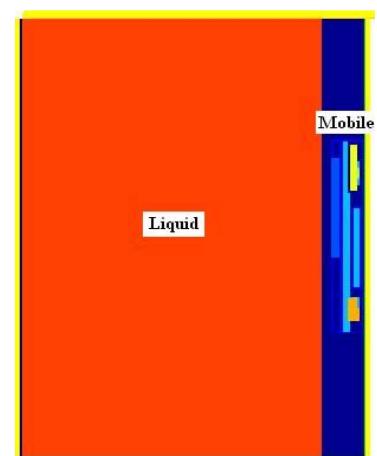

Fig. 2. Mobile phone with the liquid (plan phantom) where the SAR should be evaluated

Where $\sigma, \rho$ and $\mathrm{E}$ represent the conductivity of body tissue $(\mathrm{S} / \mathrm{m})$, the mass density of the tissue $\left(\mathrm{kg} / \mathrm{m}^{3}\right)$ and the peak electric field in tissues $(\mathrm{V} / \mathrm{m})$ respectively.

A mobile phone equipped with Wi-Fi connection allows simultaneous GSM and Wi-Fi transmission. GSM and WiFi operate on different frequency bands, i.e., the two signals are uncorrelated, and hence the SAR distributions can be summed. This is not true for correlated signals which emit at the same frequency as in the case of MIMO systems.

In most cases, multiple transmitters in portable wireless communicators operate in distinct frequency bands so the overall exposure can be determined by summing the corresponding SAR distributions. Technical report IEC 62630 [7] provides generic guidance on how to assess the exposure to multiple RF sources. The SAR evaluated for $n$ uncorrelated sources (named $\mathrm{SAR}_{\text {total }}$ ) is the sum of the SAR for each of the n sources:

$$
S A R_{\text {total }}=\sum_{1}^{n} S A R_{i}
$$

\section{SAR EVALUATION}

\section{A. One transmitter}

The GSM is based on the TDMA technique. This technique allows eight users to share the same frequency band. By this way, a mobile emits (or receives) only for one eighths of the communication time. With a constant peak output power of $2 \mathrm{~W}$, the mean power is equal to $0.250 \mathrm{~W}$. Updated standard coming from the European Telecommunication Standard Institute (ETSI) [8] defines 15 levels of PWC for GSM900 handsets (from 33 to $5 \mathrm{dBm}$ ) and GSM1800 (from 30 to $2 \mathrm{dBm}$ ). The different peak power values used for the different services are given in Table I. The maximum SAR averaged over $10 \mathrm{~g}$ of tissue for the different services are also given in Table I, while Fig. 3 shows the distribution of the SAR for the different transmitters. The values of the maximum SAR averaged over $10 \mathrm{~g}$ of tissue depend strongly on the peak power. Therefore, the maximum obtained value is for GSM900 which is high compared to values for other services. 
TABLE I

SAR10G MAXIMUM AND PEAK POWER FOR THE DIFFERENT TRANSMITTERS

\begin{tabular}{|l|c|c|}
\hline Service & $\begin{array}{c}\text { Peak power } \\
\text { (mw) }\end{array}$ & $\begin{array}{c}\text { SAR10g Max } \\
\text { (W/Kg) }\end{array}$ \\
\hline GSM900 & 250 & 1.389 \\
\hline GSM1800 & 125 & 0.256 \\
\hline UMTS2100 & 125 & 0.476 \\
\hline WIFI2400 & 100 & 0.259 \\
\hline
\end{tabular}
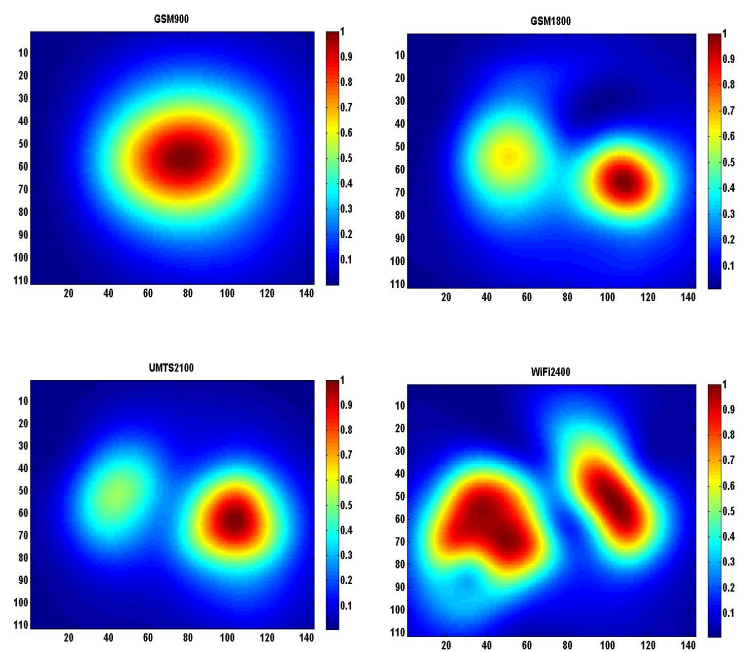

Fig. 3. Distribution of the SAR : GSM900(top left), GSM1800 (top right), UMTS2100 (bottom left), Wi-Fi (bottom right). All the values of the SAR for each figure are normalized to their maximum.

The distribution of the SAR depends on the frequency, i.e., firstly that the distributions are different for the different services utilizing separate frequencies, and secondly that the calculated maximum SAR averaged over $10 \mathrm{~g}$ of tissue depend also on the frequency and on the placement of the antenna.

\section{B. Two transmitters}

The smart phones contain multiple transmitters operating at widely spaced frequencies. User can use Wi-Fi or send a Multimedia Message Service (MMS) while making a call. In this case, user is exposed to electromagnetic field emitted by different services at the same time. In this section, the SAR is evaluated for different configurations taking all possible real combinations of the transmitters.

Note that the two different antennas are located at the top and at the bottom of the mobile as in the real case.

The top antenna is used for GSM900 and UMTS2100, it can be noticed that if it is possible in the real case to use GSM900 and UMTS2100 at the same time, the maximum SAR averaged over $10 \mathrm{~g}$ of tissue for each service will be localized very close to each other and the combined SAR value will be very high.
The results show that the calculated local SAR10g for the different combinations for the considered mobile never exceeds the limit of $2 \mathrm{~W} / \mathrm{Kg}$ given by ICNIRP.

The SAR10g is given for the different configurations in Table II. Moreover, it was confirmed that the maximum of the sum of the SAR10g evaluated from two different transmitters never reaches the sum of the maximum values evaluated from each transmitter separately.

$$
\operatorname{Max}\left(\sum_{1}^{n} \operatorname{SAR}_{i}\right) \leq \sum_{1}^{n} \operatorname{Max}\left(\operatorname{SAR}_{i}\right)
$$

This result was expected as the exposure from a transmitter depends on the frequency i.e. depend on the thickness of the tissue. The two antennas are not located in the same place. Therefore the distribution of the SAR and the location of the maximal value obtained for a service is not the same like that for another service which emits at different frequency.

Fig.4 shows the distribution of the SAR for different combinations (GSM900 Wi-Fi2400, GSM1800 Wi-Fi and UMTS2100 Wi-Fi2400). All the values of the SAR for each combination are normalized to their maximum. The maximum SAR averaged over $10 \mathrm{~g}$ of tissue for the different studied combinations are given in Table II. The sums of the maximum of SAR10g (given in Table I) for the different combinations are presented also in Table II.

\section{CONCLUSION}

SAR evaluation for different simultaneous transmission from a mobile phone using the Finite Difference Time Domain (FDTD) techniques is investigated in this paper. The main conclusion is that the calculated local SAR for the different configurations never exceeds the limit of $2 \mathrm{~W} / \mathrm{Kg}$ given by ICNIRP. It worths mentioning that our results have been obtained with the two antennas located at the top and at the bottom of the mobile as in the real case.

It was confirmed also that the maximum of the sum of the SAR evaluated from two different transmitters never reaches the sum of the maximum evaluated for each transmitter separately as the exposure depends on the frequency and hence on the thickness of the tissue layers and on the location of the antenna.

This study will be continued to evaluate the SAR for correlated sources (MIMO) with a mobile phone using multiple antennas which emit at the same frequency band. 


\section{TABLE II}

Evaluation of the SAR10g Maximum for different combinations of the different transmitters

\begin{tabular}{|l|c|c|}
\hline & $\begin{array}{c}\text { SAR10g Max } \\
\text { (First service } \\
+ \\
\begin{array}{c}\text { Second } \\
\text { service) }\end{array}\end{array}$ & $\begin{array}{c}\text { SAR10g Max } \\
\text { (First service) } \\
+ \\
\text { SAR10g Max } \\
\text { (Second service) }\end{array}$ \\
\hline GSM900+WIFI2400 & 1.479 & 1.648 \\
\hline GSM1800+WIFI2400 & 0.46 & 0.515 \\
\hline UMTS2100+WIFI2400 & 0.682 & 0.735 \\
\hline
\end{tabular}
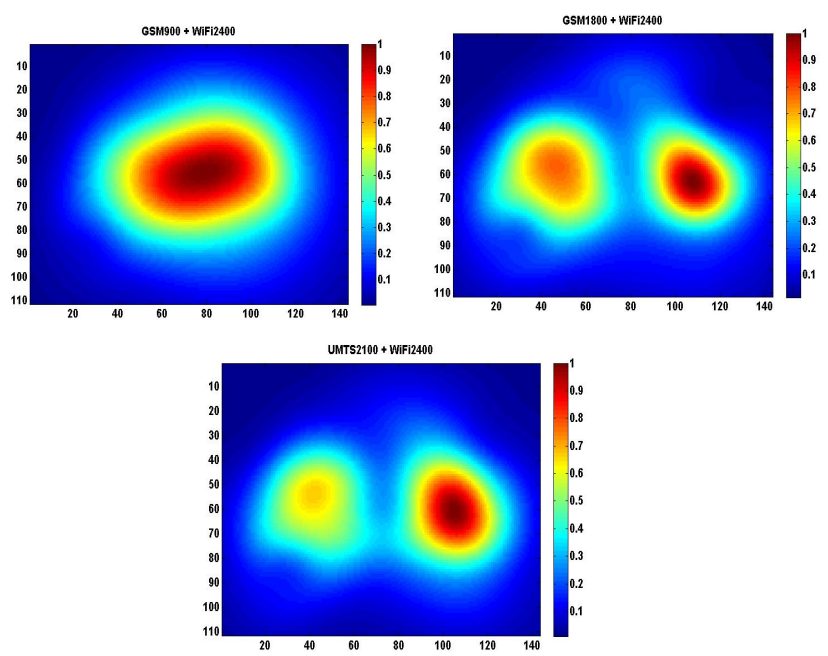

Fig. 4. SAR Distribution for two services : GSM900 + Wi-Fi (top left), GSM1800 + Wi-Fi (top right), UMTS2100 + Wi-Fi2400 (bottom), All the values of the SAR for each figure are normalized to its maximum.

\section{REFERENCES}

[1] International Commission on Non Ionizing Radiation Protection (1998). Guidelines for limiting exposure to timevarying electric, magnetic, and electromagnetic fields (up 300 GHz). Health Phys 74:494-522.

[2] IEEE Standard (1999) for Safety Levels with Respect to Human Exposure to Radiofrequency Electromagnetic Fields, $3 \mathrm{KHz}$ to $300 \mathrm{GHz}$, IEEE Standard C95.1.

[3] Comité Européen de Normalisation Electrotechnique (2008). European Committee for Electrotechnical Standardisation TC 106x WG1 EN 50492 in situ. Basic standard for the in-situ measurement of electromagnetic field strength related to human exposure in the vicinity of base stations. Brussels: CENELEC

[4] Baldauf M.A, .Pontes J.A, Timmermann J, Wiesbeck W. Mobile MIMO Phones and Their Human Exposure to Electromagnetic Fields. ICEAA 2007. Page 9.

[5] Y.Pinto, A.Ghanmi, A.Hadjem, E.Conil, T.Namur, C.Person, J.Wiart. Numerical Mobile phone models validated by SAR measurements. EuCAP 2011. Page 2585.

[6] IEC 62209-1 2005 Human exposure to radio frequency fields room hand-held and body-mounted wireless communication devices -human models, instrumentation, and procedurespart 1: procedure to determine the specific absorption rate
(SAR) for hand-held devices used in close proximity to the ear (frequency range of $300 \mathrm{MHz}$ to $3 \mathrm{GHz}$ )

[7] Technical Report IEC 62630 Ed.1 (106/173/DTR), Guidance for evaluating exposure from multiple EM sources.

[8] “ETSI Document, GSM 5.05 version 5.10,", ETS 300910 , 1996. 